\title{
Empirical Investigation of Participation on Crowdsourcing Platforms: A Gamified Approach
}

\author{
Abhishek Behl, O. P. Jindal Global University, Sonipat, India \\ (iD) https://orcid.org/0000-0002-5157-0121 \\ Pratima Sheorey, SCMHRD, SIU, Pimpri-Chinchwad, India \\ Meena Chavan, Macquarie Business School Macquarie University, Sydney, Australia \\ Kokil Jain, Amity University, Noida, India \\ Isha Jajodia, Birla Institute of Management Technology, Greater Noida, India \\ iD https://orcid.org/0000-0002-5332-3642
}

\begin{abstract}
Crowdsourcing platforms have gained importance in recent times, and their success is dependent mainly on the participation of the crowd. Participation is a function of both intrinsic and extrinsic motivation. Moreover, with the growing scale of information, the participants would need to focus on the quality of information to achieve sustainable participation. The study uses game elements and information quality grounded in motivational affordance perspective (MAP) to study the intrinsic and extrinsic participation on a crowdsourcing platform. The authors collected responses from 337 participants who are actively contributing to any crowdsourcing platform. Warp PLS uses partial least square structured equation modeling. The results confirm that the use of game elements positively promotes the participant's intrinsic and extrinsic participation. This research also confirmed that motivation is also positively moderated by the quality of information that the crowdsourcing platform shares with the participants. The results help in extending the theoretical arguments of MAP and self-determination theory.
\end{abstract}

\section{KEYWORDS}

Crowdsourcing, Gamification, Information Quality, Motivation, Self-Determination Theory

\section{INTRODUCTION}

The consistently growing online population has generated volumes of knowledge and transformed the scope of "big data analytics" (BDA). Companies worldwide invariably seek quality and quantity of data to better understand the behavior of existing and potential customers. Studies assert that the role of crowdsourcing platforms includes understanding mass sentiment (Xintong et al., 2014). Crowdsourcing platforms are interactive portals that enable like-minded people to contribute knowledge, thoughts, views, and ideas towards a common goal. This, in turn, helps in tapping the wisdom of the crowd (Ye and Kankanhalli, 2017; Goh et al., 2017; Deng et al., 2016) across disciplines like healthcare, entertainment, societal development, elections, digital marketing, etc. Geiger and Schader (2014)

DOI: 10.4018/JGIM.20211101.oa14

This article published as an Open Access article distributed under the terms of the Creative Commons Attribution License (http://creativecommons.org/licenses/by/4.0/) which permits unrestricted use, distribution, and production in any medium, provided the author of the original work and original publication source are properly credited. 
discussed four archetypes of crowdsourcing platforms (crowd rating, crowd creating, crowd solving, and crowd processing) based on a $2 \times 2$ matrix on differentiating value between contributions and deriving value from contributors. Out of the four types, crowd creation is often used to develop or derive comprehensive artifacts based on various heterogeneous contributions from the crowd. Some common examples include user-generated content on channels like YouTube, videos posted on Facebook, or knowledge drawn from platforms like Wikipedia (Morschheuser et al., 2017).

Businesses use task-based crowdsourcing activities to engage the crowd and aim to derive solutions or ideas related to a defined problem (Deng et al., 2016). Howe (2008) defines organizational task crowdsourcing as an act of hiring/recruiting/engaging large groups of undefined random individuals often addressed as solvers. These individuals undertake an organizational task through an internet-based platform either maintained by the firm or a third party. The objective of such tasks is essentially linked to the profit of the firm. Moreover, organizations employ crowdsourcing to gain insights from a random crowd about a product that has either been launched or is about to be launched in a market. Examples include contests like "Doritos- Crash the Super Bowl", "Starbucks- White Cup Contest," "Lay's -Do Us a Favour," and "Airbnb Shorts." Firms use platforms like Mechanical Turk, TopCoder, ZbJ, etc., for crowdsourcing tasks, gaining popularity, attracting advertisements, and earning commission to engage the crowd.

These platforms' common concern is the lack of crowd's continued engagement (Hossain, 2012; Kaufmann et al., 2011). Reasons include lower incentives for the crowd; irrelevant and irregular nudges to participate in activities; complex crowdsourcing platforms; vernacular and language issues; etc. (Morschheuser and Hamari, 2019; Zhu et al., 2014; Durward et al., 2016). The crowd and its continued participation determine the success of any crowdsourcing platform. Studies have claimed that crowd engagement through interactive crowdsourcing platforms has helped firms achieve better and efficient information sources (Morschheuser and Hamari, 2019; Lee et al., 2013). Sustained and meaningful crowd engagement is ensured through appropriate portal design and game mechanics application; this helps better understand crowd behavior. Lately, crowdsourcing platforms have also started using game elements to capture and prolong crowd attention. Tomnod's digital initiative employs individual core drives of Octalysis gamification, such as core drive 1\# Epic Meaning and Calling, core drive 5\#, social influence, and relatedness to promote innovation and creativity. Other examples of gamified crowdsourcing include Google Image labeler and Foldit. Google image labeler is one of the earliest examples that integrated game elements to encourage participation. Different crowdsourcing applications use a range of gamification principles depending upon their objectives and the quality of experience they seek to provide. Enhancing user experience by making it more immersive through gamification can benefit the crowdsourcing endeavour.

The process of gamification adds to the degree of enjoyment by offering intangible yet significant rewards in the process of knowledge development. Morschheuser et al. (2016) and Goh et al. (2017) postulated that gamifying a platform fosters sustainability on crowdsourcing platforms through the intrinsic motivation triggered by game mechanics. Earlier studies have also discussed the use of gaming elements like points/scores, leaderboards/rankings, badges/achievements, levels, processes, virtual teams, etc. (Morschheuser et al., 2016) to engage people on crowdsourcing platforms (Morschheuser et al., 2017). While studies have explored the intrinsically motivated behavior of participants on crowdsourcing platforms and examined how various game mechanics may contribute, the role of knowledge and information in the process has been largely overlooked (Kosonen et al., 2014). With every contribution, an additional dimension of knowledge is created or upgraded. A dense crowdsourcing platform results in the development of big data often used to understand the pattern of the crowd's contribution. Many companies add a layer of information quality (IQ) to understand the existing nature and characteristics of data and draw meaningful inferences. Recent studies also confirm that IQ plays a crucial role in helping firms decide how to operate and upgrade performance, thereby making them more competitive (Behl, 2020). 
IQ is also used in psychology; it is used to understand how people behave, and if the existing information is sufficient to generalize their behaviour. Unlike firms that deal with a customer database, a crowdsourcing platform does not support one stable, defined database as the number of contributors may vary with factors like availability, interest, and work nature. In a dynamic work environment, IQ can be instrumental in understanding the intrinsic motivation of such diversified contributors.

The complexity of gamified crowdsourcing platforms makes it all the more pertinent to understand the motivation of contributors (Martinez, 2017; Fieseler et al., 2019). While studies have tested how game artifacts lead to intrinsic motivation, it would be worthwhile to explore this association in the context of a crowdsourcing platform that is bound by different types of crowd work. Earlier studies have examined intrinsic motivation concerning crowdsourcing participation from the theoretical lens of social exchange theory, resource dependence theory, self-determination theory, etc. (Morschheuser et al., 2017; Morschheuser et al., 2019; Xi and Hamari, 2019). Also, intrinsic motivation has often been used as a mediating variable. However, its importance is greater when considered a dependent variable (Xi and Hamari, 2019; Hamari and Koivisto, 2015; Zeng et al., 2017). In this vein, to the best of the authors' knowledge, no prior study has proposed to examine the role of IQ with respect to intrinsic motivation on a gamified platform. In light of the growing complexity of data with increased user participation, IQ may enable a better understanding of how game artifacts induce and promote intrinsic motivation levels and thereby increase people's participation in crowdsourcing platforms.

The study also controls for crowdsourcee's past experience and type of crowdsourcing activity to understand how the crowdsourcing platform's information quality may be used with game mechanics to determine the intrinsic motivation of contributors leading to their participation. We draw our arguments from a motivational affordance perspective (MAP) to answer the following research questions:

RQ 1: What is the role of big data analytics culture in influencing the intrinsic motivation of participants on game artifacts driven crowdsourcing platforms?

RQ 2: How does past experience and type of crowdsourcing activity control intrinsic motivation and participation in gamified crowdsourcing platforms?

We aim to answer these questions by referring to the motivational affordance perspective (MAP) as an underlying theory; MAP is likely to offer deeper insights into contributors' psyche on the crowdsourcing platform. The rest of the paper is structured as follows:

We have performed a systematic review of the literature and proposed hypotheses based on theoretical arguments in Section 2 and Section 3. Section 4 discusses in detail the research design and steps involved therein. Results are presented in Section 5, followed by a discussion in Section 6. The study concludes in Section 7; the section also presents the future scope of work and highlights the shortcomings of the study.

\section{THEORETICAL UNDERPINNING}

\subsection{Motivational Affordance Perspective (MAP)}

The Motivational Affordance Perspective (MAP) is grounded in psychology literature. It has been primarily used to understand individuals' intrinsic motivations through proper and efficient systems (Jung et al., 2010). Zhang (2008) posits that an information system can support and enhance a person's intrinsic needs with the help of appropriate system properties. MAP offers a theoretical framework for designing information system artifacts to understand users' intrinsic motivation and behavior. While intrinsic motivation and behavior are also studied using self-determination theory, it (self-determination theory) fails to explain user behavior through information-driven system artifacts that have lately gained momentum due to internet-driven systems. Therefore, MAP has gained recent scholarly attention in the context of an information-driven system such as virtual reality e-learning environment (Shin, 2017), 
group collaborative environment (Wang et al., 2015), social media channels (Zhao et al., 2013), and digital communities (Wang and Clay, 2012). MAP assumes greater significance with increasing global digitization, especially in an environment that supports the creation and dissemination of knowledge through users' active participation (such as on crowdsourcing platforms).

The use of MAP in a crowdsourcing platform has also been studied in the past (Kavaliova et al., 2016; Zeng et al., 2017; Zheng et al., 2011). Goh et al. (2017) reported that gamification artifacts were effective (in the context of a crowdsourcing platform) in attracting and engaging users by controlling intrinsic and extrinsic motivation, which in turn controlled behavior. However, limited attention has been paid to identifying the right set of game artifacts and their effect on users' intrinsic motivation. One of the possible reasons for this gap could be that crowd work is often managed by people from different geographies, age groups, and cultural backgrounds. Therefore, pre-defined game mechanics might not be useful in standardizing how intrinsic behaviour is studied (Mitchell et al., 2018; Smith et al., 2014). Moreover, crowd work generates a large pool of information and knowledge, which resembles big data in terms of nature and properties (velocity, veracity, volume, value, and variety). Studies have previously emphasized the importance of big data culture in studying firm performance (using data and its properties to understand business better).

Motivation explains user commitment and interest in a concept. However, as individuals differ in nature, working style, and understanding, the use of classical motivational theory or a single theoretical perspective to understand behaviour might not be appropriate (Frey, 1994). Following the same line of argument, MAP integrates multiple motivational theories and classifies individual motivation under three categories - emotional need, psychological need, and social and psychological need (Zhang, 2008). The selection of game artifacts is moderated by the crowdsourcing platform's capabilities to decide which game artifact should be used to induce and improve on the participation process by intrinsic motivation.

We now discuss each of the significant needs proposed by Zhang (2008) in the context of gamification and its application in crowdsourcing. Psychological needs can be met by specific system features that help users decide how they wish to express themselves and perform in distinctive ways (e.g., supporting and promoting creation and representation of self-identity); such features enable users to complete tasks on a given system (Zhang, 2008). On a crowdsourcing platform, there is a mix of tasks linked to earning monetary or non-monetary awards, and it is essential to understand the psyche of participants (Rogstadius et al., 2011). Studies show that crowd workers mostly participate because of their capabilities to perform a task; doing so resembles an act of showing their self-identities (Deng et al., 2016; Boons et al., 2015). Therefore, the choice/selection of game artifacts would help explore users' psychological self, which corresponds to "self-presentation," thereby contributing to higher engagement on the platform (Deng et al., 2016). Studies have proposed that "self-presentation" leads to motivational activities in tasks in a digital context (Aparicio et al., 2012; Mitchell et al., 2017).

MAP postulates that social and psychological needs largely explain how and which components support users in interacting with one another and contribute towards building social bonds (Xi and Hamari, 2019; Feng et al., 2018). The clubbed effect of social and psychological needs can be experienced better on a crowdsourcing platform because of the nature of participation and involvement of contributors (Hanus and Fox, 2015). Communication plays a vital role, and the quality of information between contributors is driven by both the social and psychological behaviors of people engaged with the platform (Deng et al., 2016). The use of game mechanics induces better connectivity due to better engagement practices between contributors, thereby helping in finishing the task relatively quickly. Social and psychological aspects contribute to "social bonds" or vice versa; thus, users remain engaged for more extended periods (Hamari and Koivisto, 2013). Each of the categories of crowd work differs from the other, so there cannot be a unifying game artifact to control contributors' social and psychological behaviors (Bittner and Shipper, 2014).

Lastly, MAP helps explain human emotions by designing systems and characters that propel and magnify people's emotional self (Bittner and Shipper, 2014; Sigala, 2015; Dergousoff and Mandryk, 
2015). The context seems more relevant, especially with a crowdsourcing platform where a greater understanding of behavior is required as contributors are mostly strangers working towards a shared goal and often do not interact with one another. In other words, they work together in a shared yet unfamiliar environment (Choi et al., 2014). The use of game elements through a simulated algorithm on a crowdsourcing platform may help examine which game elements, to what extent, might generate different emotions like joy, anxiety, and competitive spirit within contributors (Ye and Kankanhalli, 2017). The crowdsourcing platform's design and the placement of "playfulness" driven game artifacts seem important for sustainable engagement.

Some studies in the past have proposed intrinsic motivation as a function of other intrinsic motivation factors like cognitive behavior, which results in self-efficacy through game mechanics (Choi et al., 2014; Kosonen et al., 2014). This holds true for a given type of crowdsourcing platform which engages users for a specific task. We have briefly discussed the scope and operational definition of crowdsourcing, gamification, and big data analytics capability, which form the primary pivots for this study.

\subsection{Crowdsourcing}

The scope and boundary of crowdsourcing have expanded recently in the information science space. It started with crowdsourcing being considered as a problem-solving phenomenon using an online platform, and it has now turned into a source of big data for firms and organizations (Kittur et al., 2013). The traditional and core essence of crowdsourcing is still grounded in the idea of using large masses of people to work towards a common or shared goal, finish tasks and solve problems using tangible and intangible resources (Estellés-Arolas et al., 2015). With time, the only thing that has transformed crowdsourcing is the advent of Web 2.0; it brought a broad audience on the internet and gave them the power to contribute in various ways. The speed and extensive outreach of the internet allow crowdsourcing platforms to achieve desired results faster than their predecessors. There are several crowdsourcing applications; thus, the phenomenon has gained popularity in the recent past (Estellés-Arolas et al., 2015; Zhang et al., 2017). Major beneficiaries of such an activity are business ventures, especially startup firms that have leveraged the power of crowdsourcing to develop their business. Lately, crowdsourcing has received significant attention from established businesses investing in both internal and external crowdsourcing. Therefore, the success of crowdsourcing channels is driven by antecedents like trust, coordination, nature of work, human capital enrolled with the crowdsourcing platform, and engagement of the crowdsourcees (crowdsourcees are people engaged with a crowdsourcing platform for performing crowd tasks) (Kauffmann and Schulze, 2011). Despite increasing contributions in the area, there remains a significant gap in terms of theoretical explanations describing the interlinkages between these antecedents. A theoretical model would thus help in establishing the degree and magnitude of relationships between different factors.

Geiger and Schader (2014) conceptualized and classified crowdsourcing systems into four categories - crowd processing, crowd solving, crowd rating, and crowd creating. Crowd processing is driven by the principle of channelizing large crowds to perform a homogenous task. The essence thereof lies in the idea of unity in diversity (Estellés-Arolas et al., 2015). The contributions of each individual are seen to be qualitatively identical, therefore, valued equally. However, despite diversity, the value of the contributions is derived from individual contributions (e.g., Galaxy Zoo and Mechanical Turk). The second classification is crowd solving, which uses the crowd's diversity to extract multiple heterogeneous solutions to a challenge. The core strength and value of this approach lies in isolated contributions (non-emergent). However, the approach is more suited to times of risks and uncertainty as such situations demand varied yet focused solutions to problems (Zheng et al., 2011; Pederson et al., 2013). Cooper et al. (2010) suggest that an activity such as crowd solving would be more effective where ideas are scarce or a lack of robust solutions to a problem. Therefore, the approach is best suited to situations with limited knowledge and understanding of a topic. The third approach is crowd creating. The objective is to develop comprehensive (emergent) and defined 
solutions based on various heterogeneous contributions. An example could be Wikipedia pages, which are created by collaborative learning and knowledge of multiple people. The fourth approach - crowd rating - works on the principle of collective assessments and predictions (the wisdom of crowds to predict or assess). The new value, in this case, is derived from a large number of homogeneous votes.

\subsection{Gamification}

Recently, there has been a lot of enthusiasm around studying the application and impact of gamification in varied contexts, such as virtual and e-learning (Liu, Yang, and Chan, 2013; Hamari et al., 2016; Toda et al., 2019), workplace engagement (Landers et al., 2017; Landers \& Armstrong, 2017), and shared or gig economy (Hamari, 2017; Köse et al., 2019), fitness and m-health (Hassan et al., 2019). Extant work has focussed on the motivational impact of gamification.

The success of crowdsourcing depends on various psychological factors like engagement (Altmeyer et al., 2016; Bowser et al., 2013; Liu et al., 2011a, 2011b; Snijders et al., 2015); attitude (Bowser et al., 2013; Dergousoff and Mandryk, 2015; Itoko et al., 2014; Kobayashi et al., 2015; Tinati et al., 2016) and motivation (Altmeyer et al., 2016; Bowser et al., 2013; Eickhoff et al., 2012; Itoko et al., 2014; Kawajiri et al., 2014). Although crowdsourcing is an area explored extensively in various disciplines, a handful of studies have measured and tested the role of participant motivation (Zheng et al., 2011; Zhao and Zhu, 2014; Brabham, 2012, Chang and Lu, 2019). Earlier studies have primarily classified motivation as either intrinsic or extrinsic, which directly or indirectly leads to participants' crowdsourcing behavior. The motivation also fosters a sense of coordination between actors and stakeholders, which helps boost crowdsourcing participation. Thus, while motivation as a construct is more individually driven, literature supports that it can also be organization or task-focused (Banerjee, Isa, \& Zainuddin, 2017). Individual motivation is further driven by perceived motivational affordance (Zhao and Zhu, 2014), nature and characteristics of tasks (Zheng et al., 2011; Kaufmann et al., 2011), and granularity of tasks (Zhao and Zhu, 2014; Nakatsu et al., 2014).

\subsection{Information Quality (IQ)}

Data have proved to be one of the most useful resources for any organization. The power of data is limited to tools and their capacity to transform raw information; data also support firms' decisionmaking. As firms and their businesses go digital, large volumes of data are generated, which may better understand the functioning of the business. Large data often yield useful information, and while studies have discussed the importance of large data, recent literature has emphasized how "information quality" (with significant data growth) may be useful for business (Mulder et al., 2016; Guo et al., 2017). It is common knowledge that firms today invest in state of the art technologies like machine learning tools, cloud computing, blockchain technologies, artificial intelligence, etc. to churn different dimensions of information quality. Management scholars have also postulated, and to a great extent proved, that IQ has helped organizations reduce cost (Dubey et al., 2019; Choi et al., 2018), increase production (Dubey et al., 2018; Giannakis and Louis, 2016), and offer new and innovative products to meet future demands (Ghasemaghaei and Calic, 2019; Choi et al., 2018). Technology scholars have proposed that the success of IQ depends on key factors like technological advancements (Andre et al., 2018; Guo et al., 2017), data generation tools (Duan et al., 2019), and data processing machines/systems (Guo et al., 2017; Lakhani et al., 2015). Recent advancements in technology indicate an important trend of enhancing IQ for better business understanding (Tortorella et al., 2020; Dwivedi et al., 2019, Delen and Zolbanin, 2018; Sivarajah et al., 2017). IQ applications include gaining competitive advantages (Dubey et al., 2019; Dalenogare et al., 2018) and understanding the drivers of business (that are mostly customers) (Satish and Yosuf, 2017).

Crowdsourcing platforms, on the contrary, use customers as knowledge partners. Thus, there lies a gap in understanding these non-conventional business models like crowdsourcing through the lens of IQ as a lot of it doesn't apply them. Hence, we argue that IQ generated through crowdsourcing platforms enables a better understanding of workforce behavior and motivation. 
It can be argued that IQ would help crowdsourcing firms design and customize game artifacts, which in turn would help understand the intrinsic motivation of contributors on a crowdsourcing platform (Feng et al., 2018). Therefore, the current study proposes a theoretical model using MAP to explain intrinsic motivation effectively. MAP helps explain how the intrinsic motivation of gig workers/ contributors on crowdsourcing platforms would translate effectively into their continuous participation. While MAP usually explains the behaviour preceding intrinsic motivation to participate, we propose to use game elements that can be moderated by psychological inputs shared by behavioural analysis enabled by IQ. The next section discusses the proposed conceptual model and presents hypotheses.

\subsection{Control Variables}

The study proposes two control variables in the study: type of crowdwork and past experience. Crowd work has been classified into four categories by Geiger and Schader (2014). As the four categories are based on the type of work performed by the users, Geiger and Schader (2014) and more recently Howcraft and Kareborn (2018) postulated that it is essential to understand that the type of work positively affects the motivation of the worker and their productivity at the workplace. These studies also confirm that the type and nature of the job also make the task difficult or easy to perform, which then moulds the participatory behaviour of the participant. We use this as a control variable in our study to understand if the same holds true when the platform is gamified as gamification also contributes to the participant's motivation on any platform. We also used the past experience as the second control variable. In the crowdsourcing literature, it is also suggested that past experience of crowd work positively impacts the performance of future work. Crowd workers tend to pick up similar work when allowed to work on the crowd working platform as they find the work to be relatively more uncomplicated (Hata et al., 2017). Additionally, recent studies on gig work, having the highest similarity with crowd work, further confirm that gig employees tend not to switch their line of work as they feel more empowered with the freedom to pick work timings and work depending upon their experience (Hong et al., 2020). This, in turn, affects their choice to reperform the same or similar work and also impacts their motivation. We propose to test the same on a gamified platform and see if past experience matters when an external cue of a gamified artifact is introduced on a crowdsourcing platform.

\section{HYPOTHESES DEVELOPMENT}

This section draws arguments from gamification and crowdsourcing literature to understand the relationship thereof. We also propose the intrinsic motivation of a contributor on any crowdsourcing platform as a joint function of self-presentation, social bonds, and playfulness, as discussed in Section 2. In contrast, gamification is discussed from the lens of various game mechanics, mostly points, badges, and leader boards, as cited by gamification literature. This section discusses both the main hypotheses and the hypotheses related to the moderating effect of big data analytics controlled artificial intelligence in the proposed framework.

The degree of interaction between people on any digital platform confirms the platform's popularity and dictates an individual's self-presentation skills on an open forum. The interaction amongst these digital natives explains their reactions to other natives (Lee et al., 2013). Humancomputer interaction allows digital natives to experience different moods depending on their interests and reactions to their thoughts. Studies have confirmed that most crowdsourcing and social media websites have designs that promote and celebrate positive feelings in an individual. Recent studies and trends also indicate that these websites have expanded their horizons by allowing the expression of emotions like sadness, anger, remorse, glory, etc. (Kusuma et al., 2018; Heeks, 2017).

Further, studies have confirmed that social media websites like Facebook and Linkedin encourage participation but rarely use game mechanics to control and measure online users' behaviour (Hamari et al., 2014; Xi and Hamri, 2019). Like social networking platforms, crowdsourcing platforms attract 
large volumes of people by offering different and structured solutions to a defined problem. Thus, it becomes more critical to understand the intrinsic motivation of contributors on these platforms as not everyone's contribution is used to complete the submission. These websites usually have a mismatch between demand and supply in terms of projects and ideas to complete the projects. Studies have confirmed that capturing the attitude of the right people can lead to the success of any crowdsourcing platform. Crowdsourcing platforms also offer every contributor gamified channels and artifacts; this creates a bond between the contributor and the website. Studies have highlighted how well these websites make a bond between different contributors to complete a task (Xi and Hamrari, 2019). Knowledge and its presentation in silos can engage individuals to an extent, but Dwivedi et al. (2019) confirm that practices like one-to-one private feedback, public recommendations, and appreciation notes may motivate contributors (Mendez et al., 2020). This, in turn, may reinforce a bond of togetherness in a socially disjoint yet close-knit community. According to social exchange theory, people would be more likely to engage in a behavior if they believed that such behavior could improve relationships (social ties) with their friends (Blau, 1964). Psychology literature argues that human beings differ in terms of personality. Hence, using a standardized approach to engage all would be inappropriate. Gamification enables the use of multiple and diverse game mechanics found to affect intrinsic motivation positively. We, therefore, propose:

H1: Use of game elements has a positive significant impact on the intrinsic motivation of contributors on a crowdsourcing platform.

A crowdsourcing platform's success lies predominantly in the participation of the crowd and the quality of solutions offered on a timely basis (Zhao and Zhu, 2014). Such platforms provide both tangible and intangible benefits to attract crowd workers (most of whom are gig workers) and exploit their motivations (Kaufmann et al., 2011; Zhao and Zhu, 2014). Psychologists and management scholars have discussed the role of intrinsic and extrinsic motivation in the success of any crowdsourcing platform (Kosonen et al., 2014; Mekler et al., 2017). While extrinsic motivation in some cases dominates intrinsic motivation (as financial benefits evoke extrinsic motivation), not every crowd work guarantees confirmed financial winnings. Therefore, the primary driver to consistently contribute to crowd work channels has to be the intrinsic motivation of the contributors as it allows the participants to be creative and experience autonomy and a competitive environment and gain social recognition (Mekler et al., 2013). Building on the arguments of Zhao and Zhu (2014), perceived motivational affordance and task granularity influence an individual's attention, and crowdsourcing platforms consider website design as one of the essential aspects when it comes to tracing intrinsic motivation.

Gamification offers an innovative and promising human-computer interactive technique applied in various management domains and has helped understand how users behave on a digital platform (Hamari et al., 2014; Seaborn and Fels, 2015). Snijders et al. (2015) discussed that the application of gamification in any crowdsourcing platform helped crowdsourcees realign their thoughts from purely rational to self-purposeful and intrinsically driven. Gamification works on the core principle of targeting user attributes like participation, engagement, loyalty, concentration, and consistency in any crowdsourced work. Huotari and Hamari (2016) used MAP to discuss how game elements acted as motivational affordances for driving intrinsic motivation. The most commonly used game artifacts include points, badges, and leader boards, which drive motivational affordance (Hamari et al., 2014). Straub et al. (2015), in their experimental study, discussed how a gamified crowdsourcing environment attracted and retained users for a longer duration compared to a non-gamified platform. While the study chose the most common game elements (points, badges, and leaderboards) and was conducted for a specific type of crowd work, there lies an important gap for testing the relationship between usage of elements and participation of crowdsourcees. Considering the theoretical arguments 
of MAP, we test gamification's effect on crowdsourcee participation on a crowdsourcing platform. We therefore propose:

$\mathrm{H} 2$ : There is a positive relationship between use of game elements and participation of crowdsourcees on a crowdsourcing platform.

Crowdsourcing platforms offer different types of tasks often classified using the guidelines of Geiger and Schader (2014). Irrespective of the subcategories of the work, the crowdsourcing platform's nature of engagement with the crowdsourcees remains important. The process of participation is a double-edged sword that benefits both the crowdsourcee and the platform. Studies claim that the benefit lies more for the crowdsourcing platform. However, participants are hooked because of the multiple tangible and intangible rewards they draw by performing tasks. Stewart et al. (2010) proposed the famous SCOUT model in the context of participation on any crowdsourcing platform; the model was based on the level of effort that crowdsourcees offered and the nature of participants' motivation. Earlier studies have discussed how internal and external motivation factors help achieve a higher degree of participation on a crowdsourcing platform; the phenomenon is mostly explained by Ryan and Deci's (2000) self-determination theory. While external motivation drives contributors to earn tangible rewards after participation, there lies a game theory model wherein there is also a possibility of not earning the expected reward. Thus, for crowdsourcing practices contingent on performance (Ryan and Deci, 2000), which may or may not offer expected tangible returns, the contributors' internal driving force would ensure the quality of work and timely submission. Brabham (2010) proposed that introjected motivation helped contributors perform better, leading to a higher chance of winning awards and accolades within the crowdsourcing community. Other intrinsic motivational factors include subjective norm and trust, both of which have proved to impact and influence behaviour and person (Mitchell et al., 2017). While a crowdsourcing platform clearly defines objectives before a participant opts-in, there may be a difference in how the objectives are phrased and the objectives in reality. This may discourage the contributor and lead to incomplete tasks and a negative impact on motivation to participate. Archak (2010) discusses how internal inspiration to perform a task keeps motivation levels high, especially when there are lesser external regulations; crowdsourcing platforms are the best examples thereof.

An internally motivated participant enjoys work and is seen to be more socially active and vice versa. Unlike a physical crowd work environment where it is easy for coordination to develop among players (Greenhill et al., 2014), a digital community lacks a personal connection with one another. Thus, a motivating environment helps to perform better. As mentioned earlier, we propose to understand the effect of self-presentation, social bonds, and playfulness on the participation of crowdsourcees. While earlier studies (Rogstadius et al., 2011; Liang et al., 2018) have discussed the mediating effect of these intrinsic factors (mostly on a pre-defined homogeneous variety of crowd work), it is important to test the same on any crowd work to extend and generalize existing MAP theoretical arguments. We therefore propose:

H3: There is a positive significant relationship between intrinsic motivation and participation on a crowdsourcing platform.

\subsection{Moderating Effect of Information Quality}

The advent of Big Data Analytics (BDA) and Artificial Intelligence (AI) significantly changed how most businesses were conducted. The application of BDA in business encompasses customer acquisition, customer engagement, predicting and maximizing profits, marketing, sales analytics, supply chain operational efficiency improvement, etc. (Dubey et al., 2019). The degree of use of BDA capability depends on processes and the involvement of people. Indeed, BDAC offers most 
of the pre-requisite conditions for any complex data analysis application and quality of information (Duan et al., 2019; Chang and Lu, 2019). It may be said that information quality forms the basis for BDA. IQ assumes greater significance in businesses and situations where data are unorganized. A crowdsourcing platform is a suitable domain for IQ applications. Theories emphasizing the importance of IQ include resource-based view theory, dynamic capabilities view theory, resource dependence theory, etc.; the significance of IQ has been acknowledged in multiple contexts such as supply chain, electronic commerce firms, cloud computing, crowdsourcing, etc. However, IQ as a moderating variable has been rarely examined. As IQ delivers scientific solutions to situations that often include human intervention, its role in understanding the contributors on any crowdsourcing platform is highly important. Moreover, as our study argues that there is no uniform mechanism to know how best we could engage the participants on any digital platforms, it becomes necessary to use the crowd's wisdom. Thus, it becomes essential to understand the use of IQ concerning two primary functions on any crowdsourcing platform: 1) determining which game mechanics should be used to understand the intrinsic motivation of participants; and 2) ensuring the appropriate use of game elements to achieve higher participation on any crowdsourcing platform. It is, therefore postulated:

H4a: IQ positively impacts the relationship between the use of game artifacts and intrinsic motivation of contributors on crowdsourcing channels.

H4b: IQ positively impacts the relationship between the use of game artifacts and participation of crowd workers on crowdsourcing channels.

Figure 1 represents the theoretical model along with all the proposed hypotheses.

Figure 1. Theoretical Framework

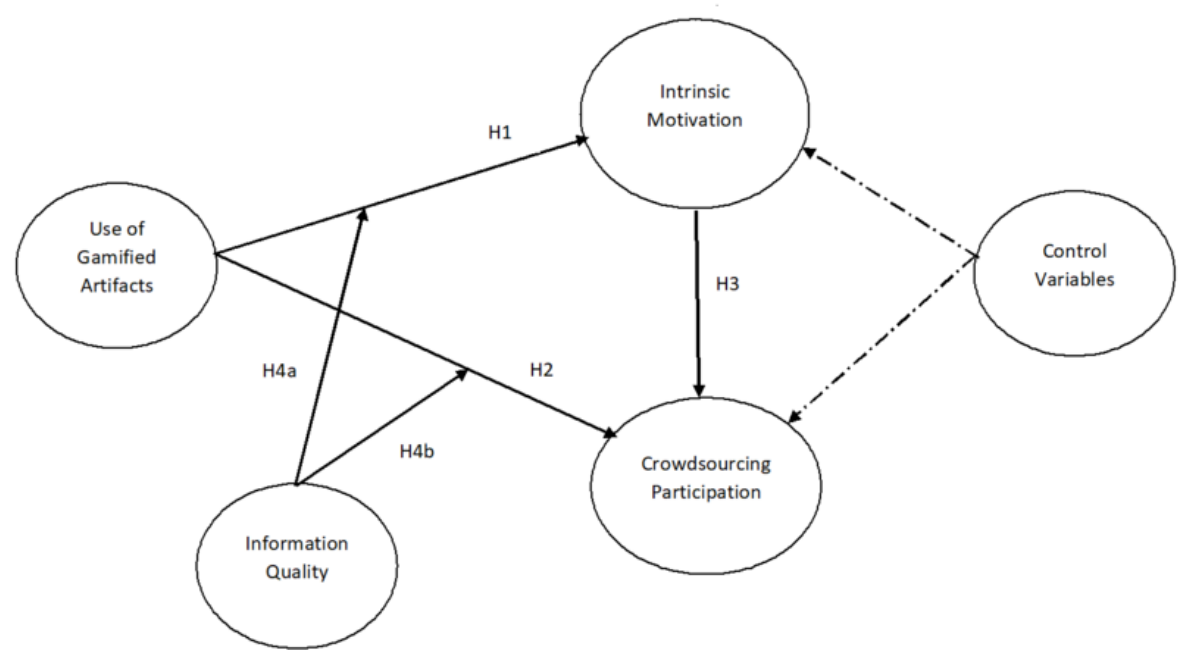




\section{RESEARCH DESIGN}

\subsection{Instrument Development}

We have used cross-sectional data to test proposed hypotheses (Refer to Figure 1); data were collected using a survey-based instrument. Each of the constructs used in the theoretical model is adapted from existing scales in literature. Each dimension was measured using a 5 point Likert scale (1 corresponds to strongly disagree, and five denotes strongly agree) (Refer to Aydiner et al., 2019; Feng et al., 2018).

The research instrument was pre-tested with 30 experts, including those from industry and academia with an average experience of 5 years handling or researching crowdsourcing platforms worldwide. The final questionnaire was shared with experts to review structure, readability, and concerns related to ambiguity and completeness (Dubey et al., 2018; 2019). Suggested changes were incorporated with the unanimous consent of experts; the questionnaire was thus finalized.

\subsection{Data Collection}

We collected data using Dillman's (2011) tailored design method guidelines. This method is well accepted and used commonly by management scholars following the empirical data collection approach (Dubey et al., 2019; Eckstein et al., 2015). Data collection was done over four months (September 2019- December 2019) using a structured and systematically designed questionnaire. The questionnaire was posted on multiple crowdsourcing channels based in India. We used a leading market research firm to contact people who had participated in one or numerous crowdsourcing activities in the past two years. We reached a total of 2348 respondents via email with an invitation letter and invited them to participate in the survey; specific details of the study were shared, and confidentiality and anonymity assured. We sent four reminders to those who did not participate in the first contact list and found 337 usable responses. The response rate of $14.35 \%$ is relatively low but was found to be slightly higher than similar studies (in the context of other countries) conducted in the recent past (e.g., Sun and Hsieh, 2018; Mulder et al., 2016). The sample size is adequate to perform analysis to test the hypotheses. A widely used minimum sample size estimation method in PLS-SEM is the "10-times rule" method (Hair, Ringle, \& Sarstedt, 2011; Kock, 2018). The average time spent on the crowdsourcing platform was 167 minutes a week, out of which 86 minutes were spent finishing a crowding task every week. A detailed profile of the respondents is presented in Table 1. Respondents were classified into four categories based on significant time spent and crowdwork performed (see Geiger and Schader, 2014). Our respondents were involved in 29\% crowd processing works, $28 \%$ crowdsolving tasks, $32 \%$ crowdrating tasks, and $11 \%$ crowdcreating works. The contributors belonged to the age group of 15- 45 years overall; maximum representation was from 25 to 35 .

We tested our data using the guidelines laid down by Armstrong and Overton (1977) for nonresponse bias by comparing the responses of the measurement items of early and late respondents. We used the response of the first and the last $25 \%$ respondents and compared them as directed by Armstrong and Overton (1977) and found that there was no significant difference between each of the measured items (observed $\mathrm{p}$ value $>0.20$ ). We also found that there was significant difference between the profiles and the response pattern of both the categories (early and late respondents). Therefore, it was concluded that the data did not suffer from non-response bias.

\section{DATA ANALYSIS AND RESULTS}

The collected data were tested for outliers and no significant outliers were found when drawing box plots. We also tested for normality using Anderson Darling test and found that the data could be treated as normal ( $p>0.025)$. Data were also checked for the assumption of constant variance. We then checked the data for multi collinearity and results reported that in our data, multi collinearity was not a major issue of concern. For all cases, results reported a value of VIF $<4.5$ which was 
Table 1. Demographic Profile of the Respondents

\begin{tabular}{|l|l|l|}
\hline Demographic Variable & Classifications & Percentage \\
\hline Time Spent of Crowdsourcing Platform (per week) & $<50$ hours & $4 \%$ \\
\hline & $50-100$ hours & $14 \%$ \\
\hline & $100-150$ hours & $7 \%$ \\
\hline & $150-200$ hours & $58 \%$ \\
\hline Experience as a crowd workers & $>200$ hours & $17 \%$ \\
\hline & $0-12$ months & $6 \%$ \\
\hline & $12-24$ months & $36 \%$ \\
\hline & $24-36$ months & $43 \%$ \\
\hline & $36-48$ months & $12 \%$ \\
\hline Type of Crowd Work & $48+$ months & $3 \%$ \\
\hline & Crowd Processing & $29 \%$ \\
\hline & Crowd Solving & $28 \%$ \\
\hline & Crowd Rating & $32 \%$ \\
\hline Age Range & Crowd Creating & $11 \%$ \\
\hline & $15-20$ years & $11 \%$ \\
\hline & $20-25$ years & $13 \%$ \\
\hline & $25-30$ years & $37 \%$ \\
\hline & $30-35$ years & $33 \%$ \\
\hline & $35-40$ years & $4 \%$ \\
\hline & $40-45$ years & $2 \%$ \\
\hline & & \\
\hline
\end{tabular}

significantly lesser than the recommended threshold of 10.0 as suggested by Hair et al. (2006). The data therefore, are free from the issue of multicollinearity.

\subsection{Measurement Model}

We calculated the value of reliability coefficient of each of the items using Cronbach's alpha and split half method, scale composite reliabilities (SCR) and average variance extracted (AVE) for each of the first order constructs with multiple items. Table 2 reports each of the mentioned values for all the constructs and their respective items wherever necessary; results confirm reliability and validity of measured constructs.

All individual factor loadings were found to be greater than 0.5 (Refer to Appendix A), and the overall scale composite reliability was greater than 0.7 with average variance explained (AVE) scores greater than 0.5 (Refer Table 2). Therefore, we can safely assume that convergent validity exists in our theoretical model (Fornell and Larcker, 1981). Referring to Table 3, we tested for discriminant validity and obtained satisfactory results. Results from Table 3 confirm that correlation between latent constructs was not greater than the square root of AVE for each of the individual constructs, which confirms discriminant validity in our model. Based on the results, we confirm construct validity for the data. We then calculated the measurement model fit indices and quality indices and found all values satisfying the required respective criterion [APC (average path coefficient) $=0.302, \mathrm{p}<0.001$; ARS (average R-squared) $=0.832, \mathrm{p}<0.001 ;$ AFVIF (average full collinearity VIF) $=2.473$, ideally 
Table 2. Loadings of the indicator variables (Cronbach's alpha, SCR and AVE)

\begin{tabular}{|c|c|c|c|c|c|c|}
\hline Construct & Item & $\begin{array}{l}\text { Factor } \\
\text { Loadings }\end{array}$ & Variance & $\begin{array}{l}\text { Error } \\
\text { (Ei) }\end{array}$ & SCR & AVE \\
\hline \multirow{8}{*}{$\begin{array}{l}\text { Information Quality } \\
\text { (IQ) } \\
(\alpha=0.85)\end{array}$} & IQ 1 & 0.69 & 0.47 & 0.53 & \multirow[t]{8}{*}{0.87} & \multirow[t]{8}{*}{0.553} \\
\hline & IQ 2 & 0.79 & 0.62 & 0.38 & & \\
\hline & IQ 3 & 0.74 & 0.55 & 0.45 & & \\
\hline & IQ 4 & 0.76 & 0.58 & 0.42 & & \\
\hline & IQ 5 & 0.67 & 0.44 & 0.56 & & \\
\hline & IQ 6 & 0.75 & 0.57 & 0.43 & & \\
\hline & IQ 7 & 0.77 & 0.59 & 0.31 & & \\
\hline & IQ 8 & 0.75 & 0.56 & 0.44 & & \\
\hline \multirow{7}{*}{$\begin{array}{l}\text { Use of Game Artefacts (GM) } \\
(\alpha=0.93)\end{array}$} & GM1 & 0.78 & 0.61 & 0.39 & \multirow[t]{7}{*}{0.82} & \multirow[t]{7}{*}{0.495} \\
\hline & GM 2 & 0.73 & 0.53 & 0.47 & & \\
\hline & GM 3 & 0.68 & 0.46 & 0.54 & & \\
\hline & GM 4 & 0.71 & 0.50 & 0.50 & & \\
\hline & GM 5 & 0.69 & 0.48 & 0.52 & & \\
\hline & GM 6 & 0.70 & 0.49 & 0.51 & & \\
\hline & GM 7 & 0.63 & 0.40 & 0.60 & & \\
\hline \multirow{8}{*}{$\begin{array}{l}\text { Intrinsic Motivation (IM) } \\
(\alpha=0.81)\end{array}$} & IM 1 & 0.68 & 0.46 & 0.54 & \multirow[t]{8}{*}{0.93} & \multirow[t]{8}{*}{0.481} \\
\hline & IM 2 & 0.72 & 0.52 & 0.48 & & \\
\hline & IM 3 & 0.66 & 0.44 & 0.56 & & \\
\hline & IM 4 & 0.57 & 0.33 & 0.67 & & \\
\hline & IM 5 & 0.65 & 0.42 & 0.58 & & \\
\hline & IM 6 & 0.69 & 0.48 & 0.52 & & \\
\hline & IM 7 & 0.76 & 0.58 & 0.42 & & \\
\hline & IM 8 & 0.79 & 0.62 & 0.38 & & \\
\hline \multirow{5}{*}{$\begin{array}{l}\text { Crowdsourcing Participation (CP) } \\
(\alpha=0.89)\end{array}$} & $\mathrm{CP} 1$ & 0.64 & 0.41 & 0.59 & \multirow[t]{5}{*}{0.85} & \multirow[t]{5}{*}{0.506} \\
\hline & $\mathrm{CP} 2$ & 0.69 & 0.48 & 0.52 & & \\
\hline & CP 3 & 0.74 & 0.55 & 0.45 & & \\
\hline & $\mathrm{CP} 4$ & 0.71 & 0.50 & 0.50 & & \\
\hline & CP 5 & 0.77 & 0.59 & 0.41 & & \\
\hline
\end{tabular}

$<3.3$ and acceptable if $<0.5$; TenenhausGoF $=0.596$, large $\left.{ }^{3} 0.36\right]$. Therefore, we can conclude that the model fit is good for our data (Sarstedt et al., 2014).

\subsection{Common Method Bias (CMB) Test Results}

Our data are empirical in nature and it is well documented that data involving human beings can be contaminated with common method bias (Wamba et al., 2019; Srinivasan and Swink, 2018). It is therefore important to assess the data with CMB test as suggested by Podsakoff et al., (2003) and Ketokivi and Schroeder (2004). We employed a split survey method and gathered data separately using two different surveys. While the respondents of both the surveys were of similar profiles and 
Table 3. Inter Construct Correlation

\begin{tabular}{|l|l|l|l|l|}
\hline & IQ & GM & IM & CP \\
\hline IQ & 0.894 & & & \\
\hline GM & 0.002 & 0.881 & & \\
\hline IM & -0.01 & 0.63 & 0.985 & \\
\hline CP & 0.03 & 0.59 & 0.61 & 0.899 \\
\hline
\end{tabular}

randomly selected from a defined population and a similar sampling frame, it was important to use split survey method in order to reduce the chance of common method bias (Eckstein et al., 2015). Additionally, we employed Harman's one-factor test by loading all the measurement items of our study onto one exploratory factor and found that the single factor explained 39.5\% of the total variance. This confirmed that the data did not suffer from common method bias. In the final stage of the CMB test, we performed a marker variable test suggested by Lindell and Whitney (2001) which controlled for common method variance. We did this by introducing an external variable in the measurement model which was ideally unrelated to the constructs in the proposed theoretical model in Figure 1. We aimed at measuring the effect of this variable in the model and found that there was no significant effect while measuring the CMV. This confirms that common method bias is not a serious concern in our study and can be ignored.

We also explored the pattern of analyses performed by information science and marketing scholars in the recent past and found that empirical researchers had considerably discussed concerns of endogeneity while working with primary data (see Dubey et al., 2019; Dubey et al., 2018). Hence, we performed the endogeneity test to address issues related to primary data collection instead of experimental data, of which the most important concern is that of causality. While marketing scholars have used experimental data for quite some time, information systems scholars have mostly relied on non-experimental data (usually cross-sectional in nature) collected over a period of time. Our analysis is inspired by the guidelines laid down by Guide and Ketokivi (2015); we performed a Durbin-WuHausman test (Davidson and Mackinnon, 1993).

In the last stage of the series of tests performed before testing the hypotheses, we checked if our data suffered from the issues of causality (Guide and Ketokivi, 2015; Abdallah et al., 2015; Kock, 2015b). We calculated the value of nonlinear bivariate causality direction ratio (NLBCDR) following the guidelines of Kock (2015) and found its value to be 0.74 which is in the acceptable range (,â 0.70$)$. We, therefore, concluded that causality was not a major concern in our study. Next, we performed hypotheses tests detailed in the following section.

\subsection{Results of Hypotheses Testing}

We have shown the results obtained from PLS-SEM analysis in Figure 2. PLS does not assume the data to be normally distributed, but to test the parametricity of the data, we ran an Anderson Darling Test the results of which are discussed in earlier sections. Following the guidelines of Peng and Lai (2012) and Dubey et al. (2019), we calculated the values of standard errors (SE's). Table 4 presents the PLS path coefficients and their corresponding p-values for all the hypotheses $(\mathrm{H} 1, \mathrm{H} 2, \mathrm{H} 3, \mathrm{H} 4 \mathrm{a}$ and H4b). We found that the paths GM $® \mathrm{IM}(\beta £=0.86 ; \mathrm{p}<0.001)$, GM $® \mathrm{CP}(\beta=0.43 ; \mathrm{p}<0.001)$ and IM ${ }^{\circledR} \mathrm{CP}(\beta £ 0.57, \mathrm{p}<0.001)$ were positively linked at 0.001 level of significance. Thus, $\mathrm{HI}, \mathrm{H} 2$ and $\mathrm{H} 3$ are supported. We then tested for the moderation effect of IQ in our model and found that $\mathrm{H} 4 \mathrm{a}(\beta £=0.38 ; \mathrm{p}<0.001)$ was supported while $\mathrm{H} 4 \mathrm{~b}(\beta £=0.04, \mathrm{p}=0.26)$ was not supported. Lastly, we tested the effect of control variables (Past Experience and Type of Crowd work) on the model. We can see from Table 4 that while "type of crowd work" holds a positive and significant effect, "past experience" of the crowd worker does not have a significant effect. We also tested the proposed 


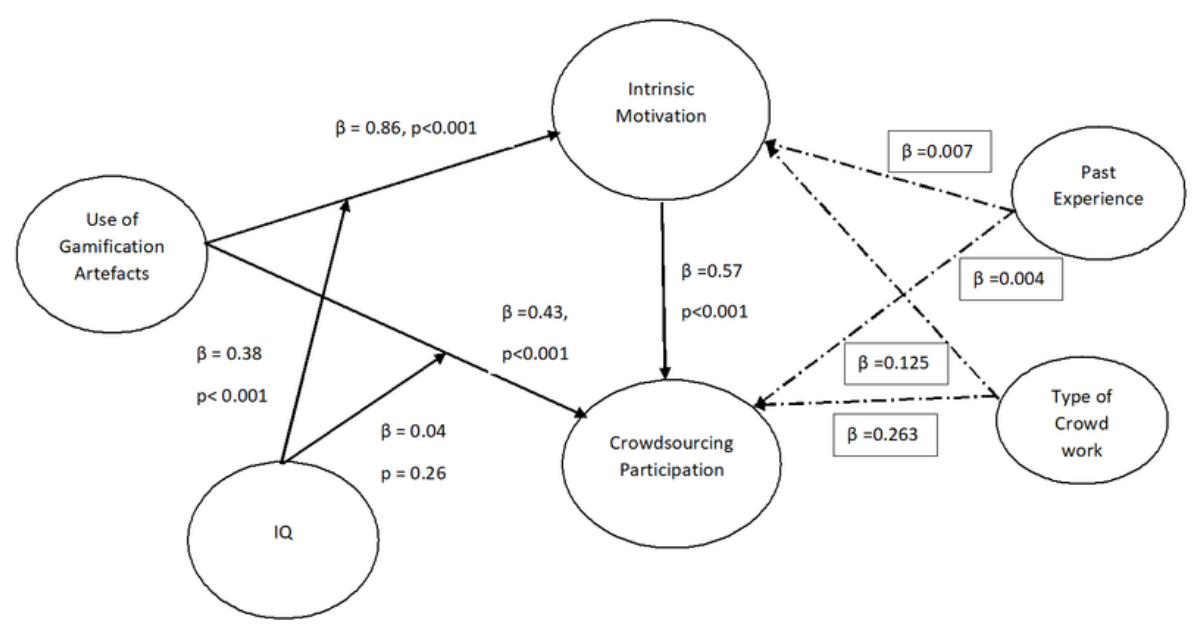

hypotheses without the presence of control variables and found that the results of H1, H2, H3 and $\mathrm{H} 4 \mathrm{a}$ as well as $\mathrm{H} 4 \mathrm{~b}$ remain the same, however the overall value of $\beta$ is relatively lower. We also calculated the value of $\mathrm{R}^{2}$ without the control variable and found that there is a significant difference between the value of $\mathrm{R}^{2}$ when control variables are not used $\mathrm{v} / \mathrm{s}$ when they are used. We also tested for the effect of the control variables both one by one and collectively and found that the value of $\mathrm{R}^{2}$ is maximum when it comes to the use of both the control variables rather than using them individually or not using them in the proposed hypothetical model.

Table 4. Structural Estimates of the hypothesized relationships

\begin{tabular}{|c|c|c|c|c|c|}
\hline Hypothesis & Effect Of & Effect On & $\boldsymbol{\beta}$ & p-value & Result \\
\hline $\mathrm{H} 1$ & GM & IM & 0.86 & $<0.001$ & Significant \\
\hline $\mathrm{H} 2$ & GM & $\mathrm{CP}$ & 0.43 & $<0.001$ & Significant \\
\hline H3 & IM & $\mathrm{CP}$ & 0.57 & $<0.001$ & Significant \\
\hline $\mathrm{H} 4 \mathrm{a}$ & IQ & GM x IM & 0.38 & $<0.001$ & Significant \\
\hline $\mathrm{H} 4 \mathrm{~b}$ & IQ & $\mathrm{GM} \times \mathrm{CP}$ & 0.04 & 0.26 & Non-significant \\
\hline \multicolumn{6}{|c|}{ Control Variables } \\
\hline & Type of CW & IM & 0.125 & $<0.001$ & Significant \\
\hline & Type of CW & $\mathrm{CP}$ & 0.263 & $<0.001$ & Significant \\
\hline & Past Experience & IM & 0.007 & 0.34 & Non-significant \\
\hline & Past Experience & $\mathrm{CP}$ & 0.004 & 0.46 & Non-significant \\
\hline
\end{tabular}




\section{DISCUSSION OF RESULTS}

There has been a radical shift in the working pattern and engagement of employees in the digital space. Both individuals and organizations are gradually moving from a conventional physical space work environment to a digital workspace, which offers flexibility and an opportunity to work on multiple assignments simultaneously (Selin et al., 2019). The trend of such engagements has been studied in the gig economy space, and crowdsourcing platforms have primarily contributed to this shift. Ye and Kankanhalli (2017) confirm that any crowdsourcing platform's success lies largely in what the platform offers to the contributors, how well platforms engage contributors, and the benefits crowd workers to draw in return. Recent arguments in literature highlight how crowdsourcing platforms have used design elements to capture the pulse of the contributors (Selin et al., 2019; Knutas et al., 2019; Mitchell et al., 2018). Gamification is one such design change that has been well accepted and adopted by practitioners. The gamified design offers a higher degree of engagement and has contributed significantly in motivating crowd workers (Morschheuser et al., 2016). A parallel school of thought also focuses on harnessing the power of IQ to enhance the business's efficiency. Firms today implement tools to handle big data and AI-powered by BDA to draw deeper business insights. Crowdsourcing literature confirms that IQ can be used for various activities like profiling, work prioritization, work allotment, matching the right resource for every task, etc. (Selin et al., 2019; Chang and Lu, 2019). While both fields explain the various aspects of crowdsourcing platforms, it becomes difficult to comprehend understanding using a theoretical lens. We, therefore, proposed hypotheses and collected empirical data to test them.

Our study reveals a significant and positive impact of gamification on intrinsic motivation and participation on a crowdsourcing platform. As our study uses self-presentation, playfulness, and social bonds as crucial drivers to intrinsic motivation, we confirm that all three traits are essential to any crowdsourcing platform's success, irrespective of the type of work (crowd processing, crowd solving, crowd creating, crowd rating). While rewards are substantial and form a key output parameter that the contributors look forward to, it becomes equally important to understand what makes the reward achievable. Results (test results of H3) also confirm that contributors high on intrinsic motivation tend to contribute continuously on the crowdsourcing platform. Our study confirms the moderating effect of IQ on the relationship between gamification and crowdsourcing platform and gamification and intrinsic motivation. We found that while IQ positively impacted the use of game elements in explaining the intrinsic motivation of contributors, the effect of the use of such tools did not gear up participation on such platforms. While the availability of data and processing capabilities are key to success for any business (Sirinivasan and Swink, 2018), it becomes important to use these resources at the right places to gain maximum advantage. Our study attempted to use IQ as a moderator to determine how different game elements could be used to understand intrinsic motivation. As crowdsourcing platforms work with diverse and large individuals, it becomes important to explore how to engage them differently, rather than using standard practice. Most of the previous studies in the gamification space have used pre-defined game elements (Mekler et al., 2013) to use and understand the target population's behavioural traits. Our study attempts to address a critical research gap by discussing the role of IQ in selecting the combination and sequence of game artifacts to better understand contributors' intrinsic motivation. Despite significant attention being given to identifying specific game mechanics and their role in driving success or boosting motivation, none of the extant work has addressed the aforementioned from the lens of IQ. We confirm from our results (Table 4) that there is a positive moderating impact of IQ on the relationship between gamification and intrinsic motivation. Hence, we have attempted to answer an important research question: What are the distinct and joint effects of gamification and intrinsic motivation on crowdsourcing platforms in an IQ moderated environment?

The results are consistent with well-established literature on intrinsic motivation and crowd worker participation in a gamified enabled digital platform (Zeng et al., 2017; Feng et al., 2018). While earlier studies have mostly focused on either specific intrinsic motivational factors or selected 
game elements or, to some extent, been restricted to a particular type of crowd work, our study offers a holistic view by addressing these concerns. Consistent with the results of Dissanayake et al. (2019) and Feng et al. (2018), we also confirm that gamification enhances intrinsic motivation among crowd workers, which in turn translates into higher participation (Mekler et al., 2017; Mekler et al., 2013). As our study is based on MAP, our results also overlap largely, with theoretical arguments proposing the use of self-determination theory to understand participants' behaviour (Seaborn and Fels, 2015; Frey and Jegre, 2001). Further, we tested our theoretical model with two control variables and found that the "past experience" of the crowdworker on the portal had no significant impact on intrinsic motivation and present participation.

Interestingly, our study posts result not in line with KÖđ[se et al. (2019), who tested for a negative impact of past experience on intrinsic motivation. On the other hand, we observe that the theoretical model holds true for people performing any type of crowd work as per the guidelines of Micheletti (2016) and Viana and Pinto (2017). One of the prime reasons for such a mixed control effect could be a lesser understanding of the participants' bifurcations and lesser/no discrimination towards the reward attached to each of them. Secondly, crowdsourcing platforms don't offer extra or higher incentives to people because of their loyalty; every crowd work is time-bound and targets bound work. These results post an interesting case for managers of crowdsourcing platforms for testing the effect of loyalty in the context of crowdsourcing channels. Our study explains the complex phenomenon and offers advancements in theory and practice. Implications are given in the following section.

\subsection{Theoretical Implications}

We offer several theoretical contributions, most of which are drawn from Feng et al. (2018)'s study on intrinsic motivation and gamification artifacts. While most of the earlier literature has used gamification either in the form of experiments or conceptualized it for crowdsourcing firms, our study offers a novel perspective to unwrap similar relationships from a theoretical viewpoint. We also extended the theoretical argument of using MAP to understand intrinsic motivation by adding a new view of big data analytics-driven artificial intelligence (Feng et al., 2018). The moderating effect of IQ proposed in the study helps harness the power of data and its ability to explain the existing phenomenon. Crowdsourcing platforms generate data at multiple stages, but earlier theoretical arguments have not used data as a resource; our study has done so in detail.

Past gamification literature has mostly focused on the most common game elements like points, badges, and leader boards to understand how they drive participant motivation on a digitally connected platform. The current research proposes a machine and data-driven system to determine which game element would be best suited to understand crowd workers' various intrinsic motivations. The study also helps reduce existing ambiguity in research concerning pre-defined game elements. It extends existing arguments of motivational affordance perspective (MAP) and applies them to any type of crowd work when treated in a machine learning-driven environment. We also extend the existing application of MAP to explain how crowd worker participation may contribute to any crowdsourcing platform and be controlled by adding a layer of game elements in existing platforms. Therefore, when selected by IQ-powered systems, game elements would help the crowdsourcing channel be more customized according to the contributor's nature (Liang et al., 2018; Durward et al., 2016). This would further help in explaining the intrinsic motivation and participation of contributors in an efficient manner. The study introduces IQ as a catalyst offering better predictability in a dynamic crowdsourcing environment if linked with gamification.

\subsection{Managerial and Practical Implications}

Our study offers a pragmatic view for crowdsourcing firms to consistently attract crowd workers (primarily gig workers) to perform tasks. Gig work is becoming increasingly popular; most of the firms today, including large corporates, seek to get their tasks done through gig workers and crowdsourcing 
platforms. Our study offers a threefold solution for three different stakeholders (demand-side, supplyside, and intermediaries) in this process of delivering crowd work.

First, we suggest that crowdsourcing channels implement BDA enabled AI tools to collect as much information as possible on crowd workers. This will also help understand the crowd's intrinsic behaviour and the flow of knowledge between crowd workers. Our study offers critical insights based on which channels may incorporate appropriate game mechanics to understand and capture crowd workers' emotions and subsequently convert negative emotions into positive ones.

Second, our study offers a better understanding of how intrinsic motivation is important to crowd workers' participation. While earlier studies separate intrinsic behaviour into various subparts, like emotional, cognitive, and psychological aspects, our study stresses that the theoretical arguments proposed by MAP may be used to understand how using different game elements could help capture crowd workers' attention. It is also known that because of the high degree of competition, not every crowd worker is rewarded. Thus, to understand, attract and maintain crowd psyche, attention and enthusiasm to contribute consistently, other behavioural theories must be employed; then, single or multiple game elements may be used to increase crowd workers' intrinsic motivation to participate in different crowdsourcing activities.

\section{CONCLUSION, LIMITATIONS AND FUTURE RESEARCH DIRECTIONS}

We have observed applied gamification in firms for quite some time; such gamification is usually used to attract crowdsources/customers/users/crowdworkers and keep them engaged. We propose to apply gamification principles to a crowdsourcing platform. Our study presents a novel moderating effect of IQ to determine which game artifact would best offer an understanding of the intrinsic motivation of crowd workers. We provide a fresh perspective on crowdsourcing studies by measuring the effect of IQ on a gamified crowdsourcing website. We borrowed arguments from MAP and integrated them with logical IQ applications under controlled environments of different types of crowdsourcing activities to generalize results; this is a unique contribution of the study. The results have helped extend the current theoretical debate and assist crowdsourcing firms in harnessing the best use of IQ to understand crowd workers' intrinsic motivation. We believe that other firms can further adapt the extended MAP model in the light of IQ to draw better insights related to customers and offer them a customized gamified platform to suit their behavioural self and help them become more involved and engaged.

\subsection{Limitations of the Study and Future Scope of Research}

Our study reports several limitations. First, unlike most studies related to gamification, which are experimental and done in a simulated environment, our study followed an empirical approach; this may have resulted in lesser accuracy in understanding causality between variables. Our study also collected data over a specific time frame with a limited amount of crowd work hosted on the crowdsourcing platform. Time-series data from the crowdsourcing website could have led to better explanatory power in the model. Future studies could consider an experimental design with timeseries data to gain deeper insights into the intrinsic motivation and participation of crowd workers.

Our study relied on MAP and used IQ as a moderator. Our study does not distinguish between and classifies crowd work based on duration and technical requirements. Such differentiation could be useful in understanding how intrinsic motivation and crowd participation interact with each other. In the future, experimental studies may be carried out to understand how the intrinsic motivation of the same crowd workers may be measured for different types of crowd works.

Lastly, our study collected data from only one crowdsourcing platform in India, while most crowd workers are of Indian origin. Thus, generalizing results to other crowdsourcing platforms may not be appropriate. Therefore, we propose to collect and compare data and results of similar hypotheses across 
multiple crowdsourcing platforms. It would be interesting to understand how IQ and choosing the right game element could help understand crowd workers' motivation across crowdsourcing channels. 


\section{REFERENCES}

Altmeyer, M., Lessel, P., \& Krüger, A. (2016, March). Expense control: A gamified, semi-automated, crowdbased approach for receipt capturing. In Proceedings of the 21st International Conference on Intelligent User Interfaces (pp. 31-42). doi:10.1145/2856767.2856790

Altmeyer, M., Lessel, P., Muller, L., \& Krüger, A. (2019, April). Combining Behavior Change Intentions and User Types to Select Suitable Gamification Elements for Persuasive Fitness Systems. In International Conference on Persuasive Technology (pp. 337-349). Springer. doi:10.1007/978-3-030-17287-9_27

André, Q., Carmon, Z., Wertenbroch, K., Crum, A., Frank, D., Goldstein, W., Huber, J., van Boven, L., Weber, B., \& Yang, H. (2018). Consumer choice and autonomy in the age of artificial intelligence and big data. Customer Needs and Solutions, 5(1-2), 28-37. doi:10.1007/s40547-017-0085-8

Aparicio, A. F., Vela, F. L. G., Sánchez, J. L. G., \& Montes, J. L. I. (2012, October). Analysis and application of gamification. In Proceedings of the 13th International Conference on Interacción Persona-Ordenador (pp. 1-2). Academic Press.

Armstrong, J. S., \& Overton, T. S. (1977). Estimating nonresponse bias in mail surveys. JMR, Journal of Marketing Research, 14(3), 396-402. doi:10.1177/002224377701400320

Bittner, J. V., \& Shipper, J. (2014). Motivational effects and age differences of gamification in product advertising. Journal of Consumer Marketing, 31(5), 391-400. doi:10.1108/JCM-04-2014-0945

Boons, M., Stam, D., \& Barkema, H. G. (2015). Feelings of pride and respect as drivers of ongoing member activity on crowdsourcing platforms. Journal of Management Studies, 52(6), 717-741. doi:10.1111/joms.12140

Bowser, A., Hansen, D., He, Y., Boston, C., Reid, M., Gunnell, L., \& Preece, J. (2013, October). Using gamification to inspire new citizen science volunteers. In Proceedings of the first international conference on gameful design, research, and applications (pp. 18-25). doi:10.1145/2583008.2583011

Brabham, D. C. (2012). Motivations for participation in a crowdsourcing application to improve public engagement in transit planning. Journal of Applied Communication Research, 40(3), 307-328. doi:10.1080/0 0909882.2012.693940

Chang, J., \& Lu, X. (2019, August). The Study on Students' Participation in Personalized Learning Under the Background of Artificial Intelligence. In 2019 10th International Conference on Information Technology in Medicine and Education (ITME) (pp. 555-558). IEEE.

Choi, J., Choi, H., So, W., Lee, J., \& You, J. (2014, June). A study about designing reward for gamified crowdsourcing system. In International Conference of Design, User Experience, and Usability (pp. 678-687). Springer. doi:10.1007/978-3-319-07626-3_64

Choi, T. M., Wallace, S. W., \& Wang, Y. (2018). Big data analytics in operations management. Production and Operations Management, 27(10), 1868-1883. doi:10.1111/poms.12838

Dalenogare, L. S., Benitez, G. B., Ayala, N. F., \& Frank, A. G. (2018). The expected contribution of Industry 4.0 technologies for industrial performance. International Journal of Production Economics, 204, 383-394. doi:10.1016/j.ijpe.2018.08.019

Delen, D., \& Zolbanin, H. M. (2018). The analytics paradigm in business research. Journal of Business Research, 90, 186-195. doi:10.1016/j.jbusres.2018.05.013

Deng, X., Joshi, K. D., \& Galliers, R. D. (2016). The duality of empowerment and marginalization in microtask crowdsourcing: Giving voice to the less powerful through value sensitive design. Management Information Systems Quarterly, 40(2), 279-302. doi:10.25300/MISQ/2016/40.2.01

Dergousoff, K., \& Mandryk, R. L. (2015, April). Mobile gamification for crowdsourcing data collection: Leveraging the freemium model. In Proceedings of the 33rd Annual ACM Conference on Human Factors in Computing Systems (pp. 1065-1074). ACM.

Dillman, D. A. (2011). Mail and Internet surveys: The tailored design method-2007 Update with new Internet, visual, and mixed-mode guide. John Wiley \& Sons. 
Dissanayake, I., Mehta, N., Palvia, P., Taras, V., \& Amoako-Gyampah, K. (2019). Competition matters! Self-efficacy, effort, and performance in crowdsourcing teams. Information \& Management, 56(8), 103158. doi:10.1016/j.im.2019.04.001

Duan, Y., Edwards, J. S., \& Dwivedi, Y. K. (2019). Artificial intelligence for decision making in the era of Big Data-evolution, challenges and research agenda. International Journal of Information Management, 48, 63-71. doi:10.1016/j.ijinfomgt.2019.01.021

Dubey, R., Gunasekaran, A., \& Childe, S. J. (2019). Big data analytics capability in supply chain agility. Management Decision, 57(8), 2092-2112. doi:10.1108/MD-01-2018-0119

Dubey, R., Gunasekaran, A., Childe, S. J., Blome, C., \& Papadopoulos, T. (2019). Big data and predictive analytics and manufacturing performance: Integrating institutional theory, resource-based view and big data culture. British Journal of Management, 30(2), 341-361. doi:10.1111/1467-8551.12355

Durward, D., Blohm, I., \& Leimeister, J. M. (2016). Crowd work. Business \& Information Systems Engineering, 58(4), 281-286. doi:10.1007/s12599-016-0438-0

Dwivedi, Y. K., Hughes, L., Ismagilova, E., Aarts, G., Coombs, C., Crick, T., \& Galanos, V. et al. (2019). Artificial Intelligence (AI): Multidisciplinary perspectives on emerging challenges, opportunities, and agenda for research, practice and policy. International Journal of Information Management, 57, 101994. doi:10.1016/j. ijinfomgt.2019.08.002

Eickhoff, C., Harris, C. G., de Vries, A. P., \& Srinivasan, P. (2012, August). Quality through flow and immersion: gamifying crowdsourced relevance assessments. In Proceedings of the 35th international ACM SIGIR conference on Research and development in information retrieval (pp. 871-880). doi:10.1145/2348283.2348400

Estellés-Arolas, E., Navarro-Giner, R., \& González-Ladrón-de-Guevara, F. (2015). Crowdsourcing fundamentals: Definition and typology. In Advances in crowdsourcing (pp.33-48). Springer. doi:10.1007/978-3-319-18341-1_3

Feng, Y., Ye, H. J., Yu, Y., Yang, C., \& Cui, T. (2018). Gamification artifacts and crowdsourcing participation: Examining the mediating role of intrinsic motivations. Computers in Human Behavior, 81, 124-136. doi:10.1016/j. chb.2017.12.018

Fieseler, C., Bucher, E., \& Hoffmann, C. P. (2019). Unfairness by design? The perceived fairness of digital labor on crowdworking platforms. Journal of Business Ethics, 156(4), 987-1005. doi:10.1007/s10551-017-3607-2

Fornell, C., \& Larcker, D. F. (1981). Evaluating structural equation models with unobservable variables and measurement error. JMR, Journal of Marketing Research, 18(1), 39-50. doi:10.1177/002224378101800104

Frey, B. S. (1994). How intrinsic motivation is crowded out and in. Rationality and Society, 6(3), 334-352. doi: $10.1177 / 1043463194006003004$

Frey, B. S., \& Jegen, R. (2001). Motivation crowding theory. Journal of Economic Surveys, 15(5), 589-611. doi:10.1111/1467-6419.00150

Geiger, D., \& Schader, M. (2014). Personalized task recommendation in crowdsourcing information systemsCurrent state of the art. Decision Support Systems, 65, 3-16. doi:10.1016/j.dss.2014.05.007

Ghasemaghaei, M., \& Calic, G. (2019). Does big data enhance firm innovation competency? The mediating role of data-driven insights. Journal of Business Research, 104, 69-84. doi:10.1016/j.jbusres.2019.07.006

Giannakis, M., \& Louis, M. (2016). A multi-agent based system with big data processing for enhanced supply chain agility. Journal of Enterprise Information Management, 29(5), 706-727. doi:10.1108/JEIM-06-2015-0050

Goh, D. H. L., Pe-Than, E. P. P., \& Lee, C. S. (2017). Perceptions of virtual reward systems in crowdsourcing games. Computers in Human Behavior, 70, 365-374. doi:10.1016/j.chb.2017.01.006

Greenhill, A., Holmes, K., Woodcock, J., Lintott, C., Simmons, B. D., Graham, G., Cox, J., Oh, E. Y., \& Masters, K. (2016, May 16). Playing with science: Exploring how game activity motivates users. Aslib Journal of Information Management, 68(3), 306-325. doi:10.1108/AJIM-11-2015-0182

Guide, V. D. R., Jr., \& Ketokivi, M. (2015). Notes from the Editors: Redefining some methodological criteria for the journal. Journal of Operations Management, 37(1), v-viii. 
Guo, K., Tang, Y., \& Zhang, P. (2017). CSF: Crowdsourcing semantic fusion for heterogeneous media big data in the internet of things. Information Fusion, 37, 77-85. doi:10.1016/j.inffus.2017.01.008

Hamari, J., \& Koivisto, J. (2013, June). Social Motivations To Use Gamification: An Empirical Study Of Gamifying Exercise. In ECIS (Vol. 105). Academic Press.

Hamari, J., \& Koivisto, J. (2015). Why do people use gamification services? International Journal of Information Management, 35(4), 419-431. doi:10.1016/j.ijinfomgt.2015.04.006

Hamari, J., Koivisto, J., \& Sarsa, H. (2014, January). Does gamification work? A literature review of empirical studies on gamification. In 2014 47th Hawaii international conference on system sciences (pp. 3025-3034). IEEE.

Hanus, M. D., \& Fox, J. (2015). Assessing the effects of gamification in the classroom: A longitudinal study on intrinsic motivation, social comparison, satisfaction, effort, and academic performance. Computers \& Education, 80, 152-161. doi:10.1016/j.compedu.2014.08.019

Heeks, R. (2017). Decent work and the digital gig economy: a developing country perspective on employment impacts and standards in online outsourcing, crowdwork, etc. Development Informatics Working Paper, (71).

Hong, H., Ye, Q., Du, Q., Wang, G. A., \& Fan, W. (2020). Crowd characteristics and crowd wisdom: Evidence from an online investment community. Journal of the Association for Information Science and Technology, 71(4), 423-435. doi:10.1002/asi.24255

Hossain, M. (2012, May). Users' motivation to participate in online crowdsourcing platforms. In 2012 International Conference on Innovation Management and Technology Research (pp. 310-315). IEEE. doi:10.1109/ ICIMTR.2012.6236409

Howe, J. (2008). Crowdsourcing: How the power of the crowd is driving the future of business. Random House.

Itoko, T., Arita, S., Kobayashi, M., \& Takagi, H. (2014, June). Involving senior workers in crowdsourced proofreading. In International Conference on Universal Access in Human-Computer Interaction (pp. 106-117). Springer.

Jung, J. H., Schneider, C., \& Valacich, J. (2010). Enhancing the motivational affordance of information systems: The effects of real-time performance feedback and goal setting in group collaboration environments. Management Science, 56(4), 724-742. doi:10.1287/mnsc.1090.1129

Kaufmann, N., \& Schulze, T. (2011). Worker motivation in crowdsourcing and human computation. Education, 17(2009), 6.

Kaufmann, N., Schulze, T., \& Veit, D. (2011, August). More than fun and money. Worker Motivation in Crowdsourcing-A Study on Mechanical Turk. In AMCIS (Vol. 11, No. 2011, pp. 1-11). Academic Press.

Kavaliova, M., Virjee, F., Maehle, N., \& Kleppe, I. A. (2016). Crowdsourcing innovation and product development: Gamification as a motivational driver. Cogent Business \& Management, 3(1), 1128132. doi:10.1080/2331197 5.2015 .1128132

Kawajiri, R., Shimosaka, M., \& Kashima, H. (2014, September). Steered crowdsensing: Incentive design towards quality-oriented place-centric crowdsensing. In Proceedings of the 2014 ACM International Joint Conference on Pervasive and Ubiquitous Computing (pp. 691-701). doi:10.1145/2632048.2636064

Ketokivi, M. A., \& Schroeder, R. G. (2004). Perceptual measures of performance: Fact or fiction? Journal of Operations Management, 22(3), 247-264. doi:10.1016/j.jom.2002.07.001

Kittur, A., Nickerson, J. V., Bernstein, M., Gerber, E., Shaw, A., Zimmerman, J., \& Horton, J. et al. (2013, February). The future of crowd work. In Proceedings of the 2013 conference on Computer supported cooperative work (pp. 1301-1318). doi:10.1145/2441776.2441923

Knutas, A., Van Roy, R., Hynninen, T., Granato, M., Kasurinen, J., \& Ikonen, J. (2019). A process for designing algorithm-based personalized gamification. Multimedia Tools and Applications, 78(10), 13593-13612. doi:10.1007/s11042-018-6913-5

Kobayashi, M., Arita, S., Itoko, T., Saito, S., \& Takagi, H. (2015, February). Motivating multi-generational crowd workers in social-purpose work. In Proceedings of the 18th ACM Conference on Computer Supported Cooperative Work \& Social Computing (pp. 1813-1824). doi:10.1145/2675133.2675255 
Köse, D. B., Morschheuser, B., \& Hamari, J. (2019). Is it a tool or a toy? How user conceptions of a system's purpose affect their experience and use. International Journal of Information Management, 49, 461-474. doi:10.1016/j.jinfomgt.2019.07.016

Kosonen, M., Gan, C., Vanhala, M., \& Blomqvist, K. (2014). User motivation and knowledge sharing in idea crowdsourcing. International Journal of Innovation Management, 18(05), 1450031. doi:10.1142/ S1363919614500315

Kusuma, G. P., Wigati, E. K., Utomo, Y., \& Suryapranata, L. K. P. (2018). Analysis of Gamification Models in Education Using MDA Framework. Procedia Computer Science, 135, 385-392. doi:10.1016/j.procs.2018.08.187

Lakhani, A., Gupta, A., \& Chandrasekaran, K. (2015, March). IntelliSearch: A search engine based on Big Data analytics integrated with crowdsourcing and category-based search. In 2015 International Conference on Circuits, Power and Computing Technologies [ICCPCT-2015] (pp. 1-6). IEEE. doi:10.1109/ICCPCT.2015.7159403

Lee, T. Y., Dugan, C., Geyer, W., Ratchford, T., Rasmussen, J., Shami, N. S., \& Lupushor, S. (2013, June). Experiments on motivational feedback for crowdsourced workers. Seventh International AAAI Conference on Weblogs and Social Media.

Liang, H., Wang, M. M., Wang, J. J., \& Xue, Y. (2018). How intrinsic motivation and extrinsic incentives affect task effort in crowdsourcing contests: A mediated moderation model. Computers in Human Behavior, 81, 168-176. doi:10.1016/j.chb.2017.11.040

Lindell, M. K., \& Whitney, D. J. (2001). Accounting for common method variance in cross-sectional research designs. The Journal of Applied Psychology, 86(1), 114-121. doi:10.1037/0021-9010.86.1.114 PMID:11302223

Liu, Y., Alexandrova, T., \& Nakajima, T. (2011a). Gamifying intelligent environments. In Proceedings of the 2011 international ACM workshop on Ubiquitous meta user interfaces (pp. 7-12). doi:10.1145/2072652.2072655

Liu, Y., Alexandrova, T., Nakajima, T., \& Lehdonvirta, V. (2011b). Mobile image search via local crowd: a user study. In 2011 IEEE 17th International Conference on Embedded and Real-Time Computing Systems and Applications (Vol. 2, pp. 109-112). IEEE. doi:10.1109/RTCSA.2011.10

Martinez, M. G. (2017). Inspiring crowdsourcing communities to create novel solutions: Competition design and the mediating role of trust. Technological Forecasting and Social Change, 117, 296-304. doi:10.1016/j. techfore.2016.11.015

Mekler, E. D., Brühlmann, F., Opwis, K., \& Tuch, A. N. (2013, October). Do points, levels and leaderboards harm intrinsic motivation? An empirical analysis of common gamification elements. In Proceedings of the First International Conference on gameful design, research, and applications (pp. 66-73). doi:10.1145/2583008.2583017

Mekler, E. D., Brühlmann, F., Tuch, A. N., \& Opwis, K. (2017). Towards understanding the effects of individual gamification elements on intrinsic motivation and performance. Computers in Human Behavior, 71, 525-534. doi:10.1016/j.chb.2015.08.048

Méndez, J. I., Mata, O., Ponce, P., Meier, A., Peffer, T., \& Molina, A. (2020). Multi-sensor System, Gamification, and Artificial Intelligence for Benefit Elderly People. In Challenges and Trends in Multimodal Fall Detection for Healthcare (pp. 207-235). Springer. doi:10.1007/978-3-030-38748-8_9

Micheletti, A. (2016, February). Motivating and involving users through gamification: a proposal. In Italian Research Conference on Digital Libraries (pp. 20-30). Springer.

Mitchell, R., Schuster, L., \& Drennan, J. (2017). Understanding how gamification influences behaviour in social marketing. Australasian Marketing Journal, 25(1), 12-19. doi:10.1016/j.ausmj.2016.12.001

Mitchell, R., Schuster, L., \& Jin, H. S. (2018). Gamification and the impact of extrinsic motivation on needs satisfaction: Making work fun? Journal of Business Research.

Morschheuser, B., \& Hamari, J. (2019). The gamification of work: Lessons from crowdsourcing. Journal of Management Inquiry, 28(2), 145-148. doi:10.1177/1056492618790921

Morschheuser, B., Hamari, J., \& Koivisto, J. (2016, January). Gamification in crowdsourcing: a review. In 2016 49th Hawaii International Conference on System Sciences (HICSS) (pp. 4375-4384). IEEE. doi:10.1109/ HICSS.2016.543 
Morschheuser, B., Hamari, J., Koivisto, J., \& Maedche, A. (2017). Gamified crowdsourcing: Conceptualization, literature review, and future agenda. International Journal of Human-Computer Studies, 106, 26-43. doi:10.1016/j. ijhcs.2017.04.005

Morschheuser, B., Hamari, J., \& Maedche, A. (2019). Cooperation or competition-When do people contribute more? A field experiment on gamification of crowdsourcing. International Journal of Human-Computer Studies, 127, 7-24. doi:10.1016/j.ijhcs.2018.10.001

Mulder, F., Ferguson, J., Groenewegen, P., Boersma, K., \& Wolbers, J. (2016). Questioning Big Data: Crowdsourcing crisis data towards an inclusive humanitarian response. Big Data \& Society, 3(2), 2053951716662054. doi:10.1177/2053951716662054

Nakatsu, R., \& Iacovou, C. (2014, June). An investigation of user interface features of crowdsourcing applications. In International Conference on HCI in Business (pp. 410-418). Springer. doi:10.1007/978-3-319-07293-7_40

Pedersen, J., Kocsis, D., Tripathi, A., Tarrell, A., Weerakoon, A., Tahmasbi, N., . . De Vreede, G. J. (2013, January). Conceptual foundations of crowdsourcing: A review of IS research. In 2013 46th Hawaii International Conference on System Sciences (pp. 579-588). IEEE. doi:10.1109/HICSS.2013.143

Podsakoff, P. M., MacKenzie, S. B., Lee, J. Y., \& Podsakoff, N. P. (2003). Common method biases in behavioral research: A critical review of the literature and recommended remedies. The Journal of Applied Psychology, 88(5), 879-903. doi:10.1037/0021-9010.88.5.879 PMID:14516251

Rogstadius, J., Kostakos, V., Kittur, A., Smus, B., Laredo, J., \& Vukovic, M. (2011, July). An assessment of intrinsic and extrinsic motivation on task performance in crowdsourcing markets. Fifth International AAAI Conference on Weblogs and Social Media.

Satish, L., \& Yusof, N. (2017). A review: Big data analytics for enhanced customer experiences with crowd sourcing. Procedia Computer Science, 116, 274-283. doi:10.1016/j.procs.2017.10.058

Seaborn, K., \& Fels, D. I. (2015). Gamification in theory and action: A survey. International Journal of HumanComputer Studies, 74, 14-31. doi:10.1016/j.ijhcs.2014.09.006

Selin, J., Letonsaari, M., \& Rossi, M. (2019). Emergency exit planning and simulation environment using gamification, artificial intelligence and data analytics. Procedia Computer Science, 156, 283-291. doi:10.1016/j. procs.2019.08.204

Shin, D. H. (2017). The role of affordance in the experience of virtual reality learning: Technological and affective affordances in virtual reality. Telematics and Informatics, 34(8), 1826-1836. doi:10.1016/j.tele.2017.05.013

Sigala, M. (2015). Gamification for crowdsourcing marketing practices: Applications and benefits in tourism. In Advances in crowdsourcing (pp. 129-145). Springer. doi:10.1007/978-3-319-18341-1_11

Sivarajah, U., Kamal, M. M., Irani, Z., \& Weerakkody, V. (2017). Critical analysis of Big Data challenges and analytical methods. Journal of Business Research, 70, 263-286. doi:10.1016/j.jbusres.2016.08.001

Smith, R., \& Kilty, L. A. (2014, December). Crowdsourcing and gamification of enterprise meeting software quality. In 2014 IEEE/ACM 7th International Conference on Utility and Cloud Computing (pp. 611-613). IEEE. doi:10.1109/UCC.2014.95

Snijders, R., Atilla, Ö., Dalpiaz, F., \& Brinkkemper, S. (2015). Crowd-Centric Requirements Engineering: A method based on crowdsourcing and gamification. Technical Report Series, (UU-CS-2015-004).

Snijders, R., Dalpiaz, F., Brinkkemper, S., Hosseini, M., Ali, R., \& Ozum, A. (2015, August). REfine: A gamified platform for participatory requirements engineering. In 2015 IEEE 1st International Workshop on Crowd-Based Requirements Engineering (CrowdRE) (pp. 1-6). IEEE. doi:10.1109/CrowdRE.2015.7367581

Srinivasan, R., \& Swink, M. (2018). An investigation of visibility and flexibility as complements to supply chain analytics: An organizational information processing theory perspective. Production and Operations Management, 27(10), 1849-1867. doi:10.1111/poms.12746

Sun, J. C. Y., \& Hsieh, P. H. (2018). Application of a gamified interactive response system to enhance the intrinsic and extrinsic motivation, student engagement, and attention of English learners. Journal of Educational Technology \& Society, 21(3), 104-116. 
Tinati, R., Luczak-Roesch, M., Simperl, E., \& Hall, W. (2016, May). Because science is awesome: studying participation in a citizen science game. In Proceedings of the 8th ACM Conference on Web Science (pp. 45-54). doi:10.1145/2908131.2908151

Tortorella, G. L., Vergara, A. M. C., Garza-Reyes, J. A., \& Sawhney, R. (2020). Organizational learning paths based upon industry 4.0 adoption: An empirical study with Brazilian manufacturers. International Journal of Production Economics, 219, 284-294. doi:10.1016/j.jpe.2019.06.023

Viana, P., \& Pinto, J. P. (2017). A collaborative approach for semantic time-based video annotation using gamification. Human-centric Computing and Information Sciences, 7(1), 13. doi:10.1186/s13673-017-0094-5

Wamba, S. F., Dubey, R., Gunasekaran, A., \& Akter, S. (2019). The performance effects of big data analytics and supply chain ambidexterity: The moderating effect of environmental dynamism. International Journal of Production Economics.

Wang, X., \& Clay, P. F. (2012). Beyond adoption intention: Online communities and member motivation to contribute longitudinally. Journal of Organizational Computing and Electronic Commerce, 22(3), 215-236. do i:10.1080/10919392.2012.696928

Wang, X., Schneider, C., \& Valacich, J. S. (2015). Enhancing creativity in group collaboration: How performance targets and feedback shape perceptions and idea generation performance. Computers in Human Behavior, 42, 187-195. doi:10.1016/j.chb.2014.02.017

Xi, N., \& Hamari, J. (2019). Does gamification satisfy needs? A study on the relationship between gamification features and intrinsic need satisfaction. International Journal of Information Management, 46, 210-221. doi:10.1016/j.jinfomgt.2018.12.002

Xintong, G., Hongzhi, W., Song, Y., \& Hong, G. (2014). Brief survey of crowdsourcing for data mining. Expert Systems with Applications, 41(17), 7987-7994. doi:10.1016/j.eswa.2014.06.044

Ye, H. J., \& Kankanhalli, A. (2017). Solvers' participation in crowdsourcing platforms: Examining the impacts of trust, and benefit and cost factors. The Journal of Strategic Information Systems, 26(2), 101-117. doi:10.1016/j. jsis.2017.02.001

Zeng, Z., Tang, J., \& Wang, T. (2017). Motivation mechanism of gamification in crowdsourcing projects. International Journal of Crowd Science.

Zhang, P. (2008). Technical opinion Motivational affordances: Reasons for ICT design and use. Communications of the ACM, 51(11), 145-147. doi:10.1145/1400214.1400244

Zhang, Q., Yang, L. T., Chen, Z., Li, P., \& Deen, M. J. (2017). Privacy-preserving double-projection deep computation model with crowdsourcing on cloud for big data feature learning. IEEE Internet of Things Journal, 5(4), 2896-2903. doi:10.1109/JIOT.2017.2732735

Zhao, Y., Liu, J., Tang, J., \& Zhu, Q. (2013, March). Conceptualizing perceived affordances in social media interaction design. In Aslib Proceedings. Emerald Group Publishing Limited. doi:10.1108/00012531311330656

Zhao, Y., \& Zhu, Q. (2014). Evaluation on crowdsourcing research: Current status and future direction. Information Systems Frontiers, 16(3), 417-434. doi:10.1007/s10796-012-9350-4

Zhao, Y. C., \& Zhu, Q. (2014). Effects of extrinsic and intrinsic motivation on participation in crowdsourcing contest. Online Information Review.

Zheng, H., Li, D., \& Hou, W. (2011). Task design, motivation, and participation in crowdsourcing contests. International Journal of Electronic Commerce, 15(4), 57-88. doi:10.2753/JEC1086-4415150402

Zhu, H., Djurjagina, K., \& Leker, J. (2014). Innovative behaviour types and their influence on individual crowdsourcing performances. International Journal of Innovation Management, 18(06), 1440015. doi:10.1142/ S1363919614400155 


\section{APPENDIX A. OUTPUT OF EXPLORATORY FACTOR ANALYSIS (EFA)}

\begin{tabular}{|c|c|c|c|c|c|c|}
\hline Item & IQ & GM & IM & $\mathrm{CP}$ & S.E. & P-value \\
\hline IQ 1 & 0.75 & & & & 0.056 & $<0.001$ \\
\hline IQ 2 & 0.78 & & & & 0.052 & $<0.001$ \\
\hline IQ 3 & 0.71 & & & & 0.051 & $<0.001$ \\
\hline IQ 4 & 0.69 & & & & 0.054 & $<0.001$ \\
\hline IQ 5 & 0.79 & & & & 0.054 & $<0.001$ \\
\hline IQ 6 & 0.75 & & & & 0.052 & $<0.001$ \\
\hline IQ 7 & 0.77 & & & & 0.056 & $<0.001$ \\
\hline IQ 8 & 0.68 & & & & 0.057 & $<0.001$ \\
\hline GM1 & & 0.79 & & & 0.051 & $<0.001$ \\
\hline GM 2 & & 0.73 & & & 0.053 & $<0.001$ \\
\hline GM 3 & & 0.65 & & & 0.055 & $<0.001$ \\
\hline GM 4 & & 0.70 & & & 0.055 & $<0.001$ \\
\hline GM 5 & & 0.79 & & & 0.056 & $<0.001$ \\
\hline GM 6 & & 0.74 & & & $0 / 053$ & $<0.001$ \\
\hline GM 7 & & 0.67 & & & 0.054 & $<0.001$ \\
\hline IM 1 & & & 0.82 & & 0.057 & $<0.001$ \\
\hline IM 2 & & & 0.73 & & 0.053 & $<0.001$ \\
\hline IM 3 & & & 0.75 & & 0.053 & $<0.001$ \\
\hline IM 4 & & & 0.68 & & 0.054 & $<0.001$ \\
\hline IM 5 & & & 0.70 & & 0.055 & $<0.001$ \\
\hline IM 6 & & & 0.76 & & 0.052 & $<0.001$ \\
\hline IM 7 & & & 0.72 & & 0.056 & $<0.001$ \\
\hline IM 8 & & & 0.69 & & 0.052 & $<0.001$ \\
\hline CP 1 & & & & 0.73 & 0.056 & $<0.001$ \\
\hline $\mathrm{CP} 2$ & & & & 0.71 & 0.055 & $<0.001$ \\
\hline CP 3 & & & & 0.79 & 0.056 & $<0.001$ \\
\hline $\mathrm{CP} 4$ & & & & 0.68 & 0.053 & $<0.001$ \\
\hline CP 5 & & & & 0.72 & 0.052 & $<0.001$ \\
\hline
\end{tabular}




\begin{abstract}
Abhishek Behl $(P h D)$ is a researcher in the area of information technology and analytics. He has earned his second Ph.D. from the Indian Institute of Technology, Bombay where his research is in the area of crowdfunding and gamification. He holds a rich experience of teaching, research, and consultancy. He has taught subjects like Business Analytics; Marketing Analytics; Digital Marketing; Marketing Research at colleges like SCMHRD; SP Jain etc. He has also served as a Senior Manager-Research at Centre for Innovation Incubation and Entrepreneurship, IIM Ahmedabad. His research is in the area of business analytics and decision sciences with a focus on gamification, stakeholder engagement, sustainability, and e-commerce start-ups. He has also won research grants from NASMEI and Emerald Publishers for research proposals in the area of information technology and its application in stakeholder engagement. He has presented his research work in reputable international forums like The World Bank; United Nations University; Decision Science Institute, etc.
\end{abstract}

Pratima Sheorey did her MBA in Marketing from the University of Pune and has more than 17 years of experience in the academic and corporate sector. She has worked with ORG-MARG (now ACNielsen), the Hero Group and others in the corporate sector and has been a faculty at various Institutes of Symbiosis International University (SIU). She has worked in the area of Market Research, Training \& Consulting and Business Development. Pratima has trained executives in many organisations in India and abroad in various behavioral and functional programmes like Service Orientation, Selling Skills, Creativity and Innovation etc. across levels. She has published many papers in reputed journals and participated in many conferences in India and abroad. Research interests: Customer Engagement, Experiential Marketing, Consumer Behavior, Value Creation, Co-creation of value by customer, etc.

Meena Chavan (PhD) Bcom, Mcom, PhD (International Business), SFHEA, holds the position of a Senior Lecturer, Program Director Master of International Business at the Macquarie Business School Focussed in the discipline of International Management/ Business \& Entrepreneurship, Meena is an ardent and dedicated broad-spectrum Business/Management Researcher. The hallmark of her scholarship strategy is applying multi-disciplinary and interdisciplinary perspectives to understand and explain broader business issues so that it complements and exemplifies her highly integrated practice and outlines my participation in industry-based research, grants and teaching. She publishes in the areas of International Business/Management/Business/Cross Cultural management, International Entrepreneurship, Experiential L\&T and on the Emerging market of India.

Kokil Jain is a Professor and Area Chairperson in the area of Marketing at Amity International Business School, Amity University Noida. She is a Doctorate in Management with over 16 years of experience in the field of teaching and research. She has several research publications in Scopus \& ABDC listed journals, which include $A$ and $B$ categorized publications. Her teaching area includes Consumer Behaviour and Brand Management. Her current research interest is in the area of Brand Transgressions, Brand Hate, and Online Incivility.

Isha Jajodia is an Academic Associate at Birla Institute of Management Technology, Gr. Noida, India. She is a faculty of Marketing and her research interests include consumer brand relationship, online consumer culture, service transgression, and brand management. She has several publications in indexed journals and has presented her research work in many conferences at prestigious institutes. 